\title{
Remote Raman Spectroscopy of Minerals at Elevated Temperature Relevant to Venus Exploration
}

\author{
Shiv K. Sharma ${ }^{a}$, Anupam K. Misra ${ }^{a}$ and Upendra N. Singh ${ }^{b}$ \\ ${ }^{a}$ Hawaii Institute of Geophysics and Planetology, University of Hawaii \\ 1680 East-West Road, POST 602, Honolulu, HI-96822, USA \\ bNASA Langley Research Center, Hampton, VA-23681, USA
}

\begin{abstract}
We have used a remote time-resolved telescopic Raman system equipped with $532 \mathrm{~nm}$ pulsed laser excitation and a gated intensified CCD (ICCD) detector for measuring Raman spectra of a number of minerals at high temperature to 970 K. Remote Raman measurements were made with samples at 9-meter in side a high-temperature furnace by gating the ICCD detector with 2 micro-sec gate to minimize interference from blackbody emission from mineral surfaces at high temperature as well as interference from ambient light. A comparison of Raman spectra of gypsum $\left(\mathrm{CaSO}_{4} \cdot 2 \mathrm{H}_{2} \mathrm{O}\right)$, dolomite $\left(\mathrm{CaMg}\left(\mathrm{CO}_{3}\right)_{2}\right)$, and olivine $\left(\mathrm{Mg}_{2} \mathrm{Fe}_{2-\mathrm{x}} \mathrm{SiO}_{4}\right)$, as a function of temperature shows that the Raman lines remains sharp and well defined even in the high-temperature spectra. In the case of gypsum, Raman spectral fingerprints of $\mathrm{CaSO}_{4} \cdot \mathrm{H}_{2} \mathrm{O}$ at $518 \mathrm{~K}$ were observed due to dehydration of gypsum. In the case of dolomite, partial mineral dissociation was observed at $973 \mathrm{~K}$ at ambient pressure indicating that some of the dolomite might survive on Venus surface that is at $\sim 750 \mathrm{~K}$ and 92 atmospheric pressure. Time-resolved Raman spectra of low clino-enstatite $\left(\mathrm{MgSiO}_{3}\right)$ measured at $75 \mathrm{~mm}$ from the sample in side the high-temperature furnace also show that the Raman lines remains sharp and well defined in the high temperature spectra. These high-temperature remote Raman spectra of minerals show that time-resolved Raman spectroscopy can be used as a potential tool for exploring Venus surface mineralogy at shorter $(75 \mathrm{~mm})$ and long $(9 \mathrm{~m})$ distances from the samples both during daytime and nighttime. The remote Raman system could also be used for measuring profiles of molecular species in the dense Venus atmosphere during descent as well as on the surface.
\end{abstract}

Keywords: Venus, telescopic Raman instrument, time-resolved Raman spectroscopy, high-temperature Raman spectra, mineralogy, Raman spectra of molecular gases

\section{INTRODUCTION}

Raman spectroscopy (RS) has been proposed as a candidate analysis system for missions to Mars, and more recently as a potential mineralogical analysis system to Venus. This technique has several distinct advantages over other spectroscopic techniques that have been used on past missions. For planetary applications, the sharpness of Raman spectral features of minerals allows for much less ambiguous detection, especially in the presence of mixtures. Visible, near-infrared, thermal, and reflectance and emission spectroscopy of minerals and compounds all suffer from broad overlapping spectral features[1] which complicate interpretation of their spectra. Small portable remote Raman systems, which are suitable for planetary rovers and landers, have been shown to be effective in identifying hydrous and anhydrous minerals, glasses of mineral compositions, and ices. The remote Raman systems developed at the University of Hawaii have been tested from $9 \mathrm{~m}$ to $\geq 100 \mathrm{~m}$ distance [e.g., Refs. 2-7]. Two of the most important advantages of time-resolved (TR) RS have over other techniques for a mission to Venus is its rapid mineralogical analysis of both hydrous and anhydrous minerals and stand-off analysis at distances of many meters. Rapid mineralogical analysis and stand-off analysis are very important to missions to Venus due to the harsh environment at the planet surface. From the Venera missions it is known that on the Venusian surface the pressures are approximately $9.1 \mathrm{MPa}(90 \mathrm{~atm})$ and the temperature is near $735 \mathrm{~K}$ [8]. For these reasons, the Soviet Venera surface probes had operational lifetimes of less than 2 hours. The major gas in Venus atmosphere is $\mathrm{CO}_{2}$, and under Venusian atmospheric condition $\mathrm{CO}_{2}$ exists in a supercritical phase near the surface. In 2003, the National Research Council recommended in its Solar System Exploration Decadal Survey [9] that "NASA commit to significant new investments in advanced technology so that 
future high-priority flight missions can succeed." These proposed high-priority flight missions were further discussed in NASA's 2006 Solar System Exploration Roadmap [10]. Currently Venus is under consideration for NASA's New Frontier Program. The Venus Exploration and Analysis Group (VEXAG) has recommended that NASA should include Venus In-situ Explorer (VISE) in Announcement of Opportunities (AO) of New Frontiers Class mission for 2008 [11]. The Explorer will be investigating the composition and surface properties of Venus. It will also acquire and characterize a core sample from the surface of Venus, and it will measure the elements and mineralogy of surface materials. VEXAG has also recommended that NASA should initiate a study of a Venus Flagship Mission at earliest opportunity [11]. In light of these future NASA missions, it is beneficial to evaluate different analysis methods such as remote TR Raman spectroscopy, which offer to greatly increase the scientific return from such a mission.

Currently we have begun to evaluate TR remote Raman spectroscopic detection in an environment with temperatures similar to those found on Venus. Although the pressure of Venus (91 atm) has not been taken into account in these experiments, it is anticipated that it will not affect Raman analytical capability. Blackbody radiation at high temperature could interfere with Raman spectroscopic measurements. Time-resolved Raman spectroscopy with pulsed $532 \mathrm{~nm}$ laser has been shown to be an effective technique for high-temperature Raman spectroscopy [12]. Previous work has shown that the high temperatures can have a strong effect on the Raman spectra of minerals [12-13]. These temperature effects include broadening of Raman lines, decrease in the intensity of Stokes-Raman lines, phase transitions in minerals, dehydration and de-carbonation of minerals. High-pressure and high-temperature studies have been conducted on minerals at very high-pressures -10 's to 50's $\mathrm{GPa}$ in diamond anvil cells (e.g., [12-13]). The results of these investigations show that the Raman spectra of minerals at Venus surface pressure of 90 atm will only show small changes in the positions of Raman lines. However, dehydration and de-carbonation of minerals could be affected significantly by high atmospheric pressure of $\mathrm{CO}_{2}$ on Venus. Here we show results from a remote Raman study of minerals to $973 \mathrm{~K}$, and of $\mathrm{CO}_{2}$ gas at 1 atm at $9 \mathrm{~m}$, which demonstrates the feasibility of using this technique for mineralogical analyses and atmospheric studies at Venusian surface.

\section{INSTRUMENTATION AND EXPERIMENTAL METHOD}

\section{Time-resolved Remote Raman system}

In a conventional Raman system utilizing a CW laser, a sample is excited with a continuous beam of photons but only a very small fraction of these incident photons generate Raman signals, because of low Raman cross-section. In such systems, Raman spectra are collected by integrating the signal over several seconds under dark conditions, which helps in maintaining low background noise. When exposed to daylight, these systems become unusable, because the detector becomes oversaturated from the high background light level. Because of high surface temperature $(\sim 735 \mathrm{~K})$ on Venus surface, the thermal blackbody radiation from the sample will also interfere with the Raman spectra of minerals.

One solution to this problem is to generate large numbers of Raman photons in a relatively short time and then detect them more efficiently. A remote Raman system for daytime operation has two critical components: (1) a pulsed laser and (2) a gated detector. A time-resolved Raman system significantly improves the Raman signal-to-background noise ratio and successfully measures Raman spectra in daylight as well as from the samples that are at high temperature. Using a laser with pulse widths of a few nanoseconds, the target is excited with large numbers of photons within the nanosecond time frame. The Raman phenomenon decays quickly, producing a signal, which lasts only a few nanoseconds after the laser pulse exposure. If the detector is only activated within this small time window, the number of Raman photons is large in comparison to the background photons, resulting in high signal-to-background ratio. In general, the number of Raman photons generated is directly proportional to the pulse energy of the laser. Likewise, the amount of background light detected by the system is directly proportional to the gate width of the detector. Therefore, precise time-gating of the detection system is critical in capturing a maximum number of Raman photons and minimum background light energy.

The directly coupled and portable remote pulsed Raman system used in the current investigations is described in detail elsewhere [4-7], and a schematic diagram of the system is shown in Fig. 1. The remote time-resolved Raman system consists of an 8-inch (203.2 mm) diameter telescope (Meade LX-200R Advanced Ritchey-Chertien, f/10), a frequencydoubled mini Nd:YAG pulsed laser source (model Ultra CFR, Big Sky Laser, $532 \mathrm{~nm}, 35 \mathrm{~mJ} /$ pulse, $20 \mathrm{~Hz}$, pulse width 8 $\mathrm{ns}$, central laser spot divergence $\sim 0.5 \mathrm{mrad}$ ), and a Kaiser Optical Systems f $/ 2.2$ HoloSpec spectrometer equipped with a gated, thermo-electrically cooled ICCD detector. The telescope is directly coupled to the spectrometer through a camera lens $(50 \mathrm{~mm}, \mathrm{f} / 1.8)$. A 532-nm holographic SuperNotch filter (SNF) is placed in front of the camera lens to minimize the reflected and Rayleigh scattered photons from the target. The signal is then directed through a fixed mechanical slit of 
$100 \mu \mathrm{m}$ width into the spectrograph. The entire system is mounted atop a pan-and-tilt scanner, which is electronically controlled, on a portable trolley. Since the entire system moves together, optical alignment between the laser, telescope, and spectrograph is always maintained when the system is configured in the co-axial mode. A 10x beam expander is mounted in front of the laser to allow focusing of the laser spot at targeted distances. After focusing, the laser spot size is typically $1 \mathrm{~mm}$ in diameter at $50 \mathrm{~m}$ distance. For Raman measurements, the laser beam diameter at the sample is kept to $7 \mathrm{~mm}$. The laser is operated at $35 \mathrm{~mJ} /$ pulse with a frequency of $20 \mathrm{~Hz}$. The HoloSpec spectrograph is equipped with a volume phase holographic grating capable of measuring Stokes-shifted Raman spectra in the range of 50 to $2500 \mathrm{~cm}^{-1}$. For some analyses, this grating was replaced by a HoloPlex grating (Kaiser Optical Systems) which extends the spectral range to $4500 \mathrm{~cm}^{-1}$ while maintaining a resolution of $7 \mathrm{~cm}^{-1}$.

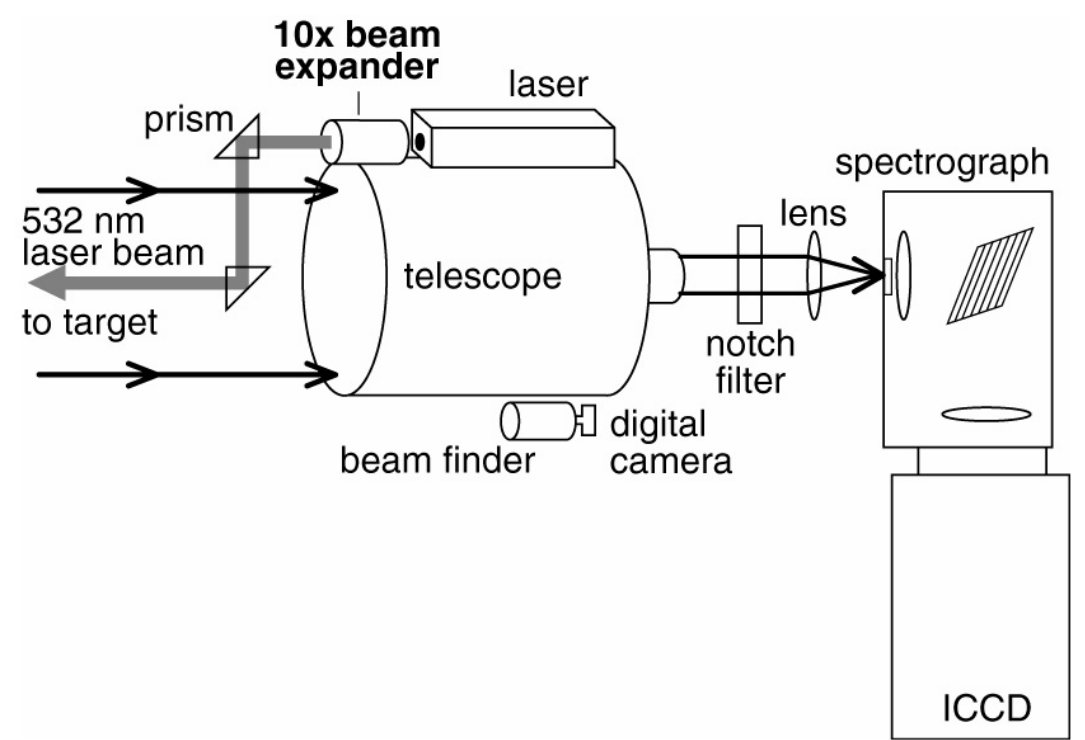

Fig. 1. Schematic diagrams of directly coupled remote time-resolved Raman spectrograph systems shown in coaxial geometry.

All spectra presented here were measured with the ICCD detector operating in the gated mode. For timing purposes, trigger signals generated by the flash lamp of the laser were used as a reference. The gate delay of the ICCD detector was adjusted so that it opened at the same time as the arrival of the first Raman signal. In general, since the pulse width of our Nd:YAG laser is $8 \mathrm{~ns}$, the optimum detector gate width is expected to be only a few nanoseconds, during which Raman photons are arriving. However, due to slight fluctuations of the electronics in the laser, laser pulses are not consistently generated with the exact same time interval. In this study, fluctuations in the pulse generation are on the order of $\pm 1 \mu \mathrm{s}$. Hence, a gate width of $2 \mu \mathrm{s}$ was used to capture Raman signals excited by the laser pulses. Samples were also measured with an integration time of $1 \mathrm{~s}$, which is equivalent to exposure of 20 laser pulses for our system operating at $20 \mathrm{~Hz}$ with pulse energy of $35 \mathrm{~mJ} /$ pulse.

No cosmic ray or baseline corrections were applied to the spectra presented in this study. This is an additional advantage of using the gated mode: the ICCD acquires the spectrum only during the interval for which the gate is open, and a gate width of $2 \mu$ s significantly reduces the probability of capturing a cosmic ray. Thus, most spectra are free from cosmic peaks.

With short-distance $(\sim 10 \mathrm{~m})$ remote Raman systems, we commonly use the atomic emission lines of a neon lamp to calibrate our spectrometer. In addition, liquid cyclohexane and atmospheric nitrogen (band at $2331 \mathrm{~cm}^{-1}$ ) were used as Raman standards to calibrate the system (cyclohexane peak positions were obtained from the NIST website [14]). The Raman peak positions of various minerals reported here are within $\pm 2 \mathrm{~cm}^{-1}$ of their standard literature values. Two commercial computer programs were used for data collection and spectral processing: WinSpec ${ }^{\circledR}$, a 32-bit Windows software package (Roper Scientific) for spectral data acquisition, and GRAMS/32 ${ }^{\circledR}$ software package (Galactic Industries) for data processing. 


\section{High Temperature Furnace}

Mineral samples were heated to high temperature in a windowless furnace at $9 \mathrm{~m}$ from the telescope show in Fig.2. The furnace is heated with a platinum- $10 \%$ Rhodium wire and a temperature up to $1400 \mathrm{~K}$ can be achieved. The mineral is place in side the furnace close to the center on a ceramic tube, and the laser beam is focused with the 10x beam expander mounted on the top of the telescope. The backscattered light from the sample is collected by the telescope and focused on the slit of the gated Raman spectrometer.

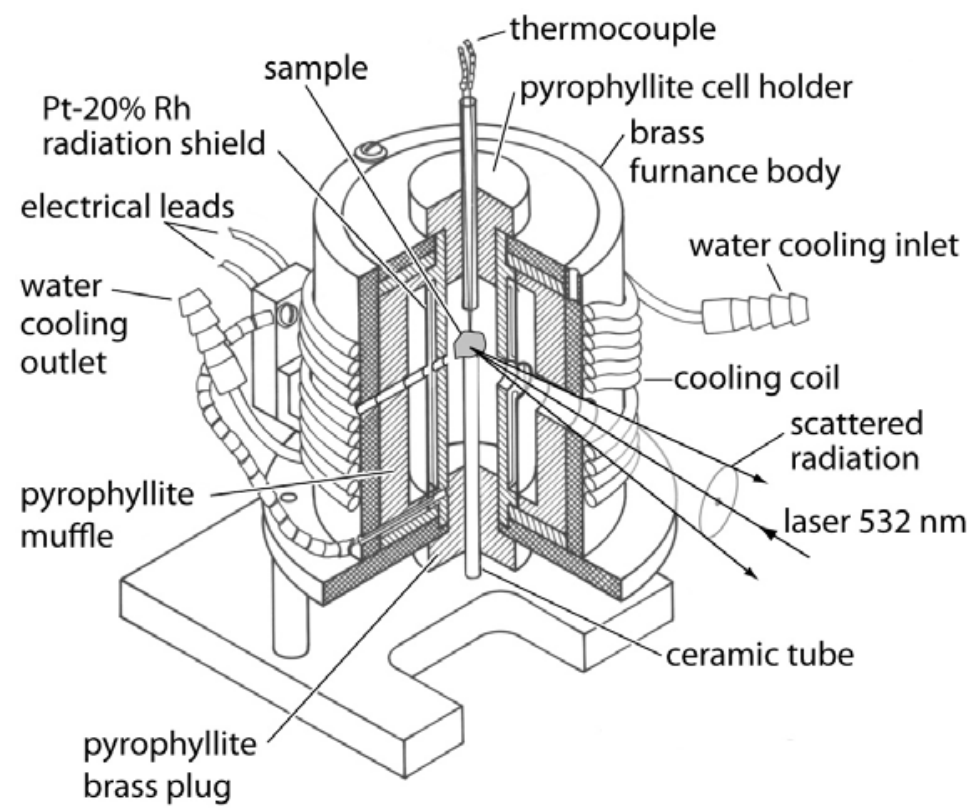

Fig.2. A windowless Pt-10\%Rh wire-wound furnace for measuring Raman spectra of minerals at high temperature.

\section{Mineral Samples}

The rock-forming minerals (dolomite, gypsum and dunite rock) were purchased from Ward's Natural Science Establishment, Inc., Rochester, New York. The polycrystalline dolomite sample was from Bamble, Norway. Gypsum of the selenite variety was from Washington County, Utah, USA. Dunite rock contained $90 \%$ fine grain olivine crystal and was from Balsam, North Carolina, USA. The low clino-enstatite crystals were provided by Professor Subrata Ghose of University of Washington. A small fragment of these samples were mounted inside the furnace and was excited with

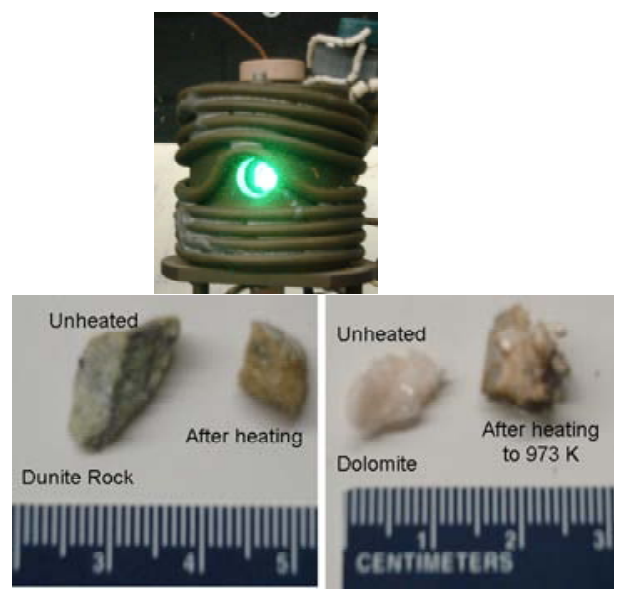

Fig. 3. Photographs of the high-temperature furnace and of dunite and dolomite sample before and after heating. Furnace is not to scale. 
532-nm pulsed laser without further cleaning or polishing. Figure 3 shows the high-temperature furnace and the samples before and after heating for Raman measurements. The dunite sample changes color because of oxidation of olivine in the air at high temperature.

\section{RESULTS AND DISCUSSION}

Time-resolved Raman spectra of gypsum in the ranges $100-2400 \mathrm{~cm}^{-1}$, and $3000-3800 \mathrm{~cm}^{-1}$ at $9 \mathrm{~m}$ and at 303,373 and $518 \mathrm{~K}$ are shown in Figs. 4 and 5, respectively. The line widths of the strongest Raman line at $1008 \mathrm{~cm}^{-1}$ of $v_{1}\left(\mathrm{SO}_{4}\right)$,

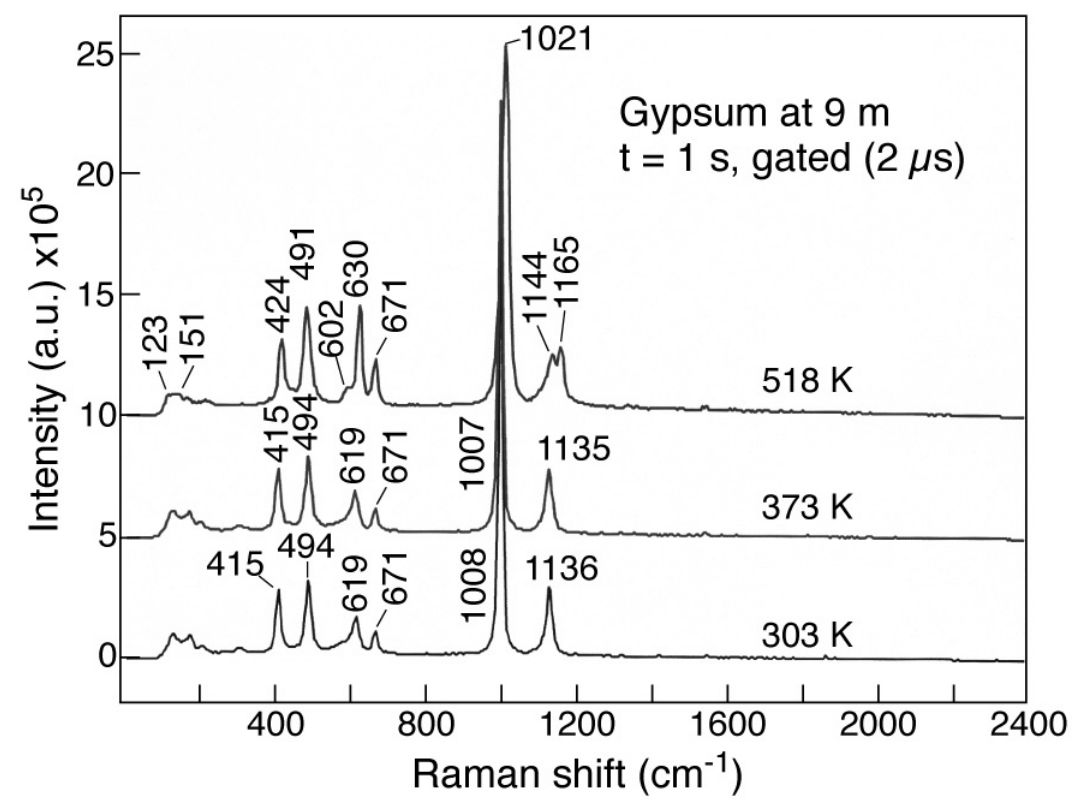

Fig. 4. Time-resolved high-temperature Raman spectra of gypsum at $9 \mathrm{~m}$ in the $100-2400 \mathrm{~cm}^{-1}$ region. Laser $532 \mathrm{~nm}, 20 \mathrm{~Hz}, 35 \mathrm{~mJ} /$ pulse, averaged over 20 pulses (1 s)

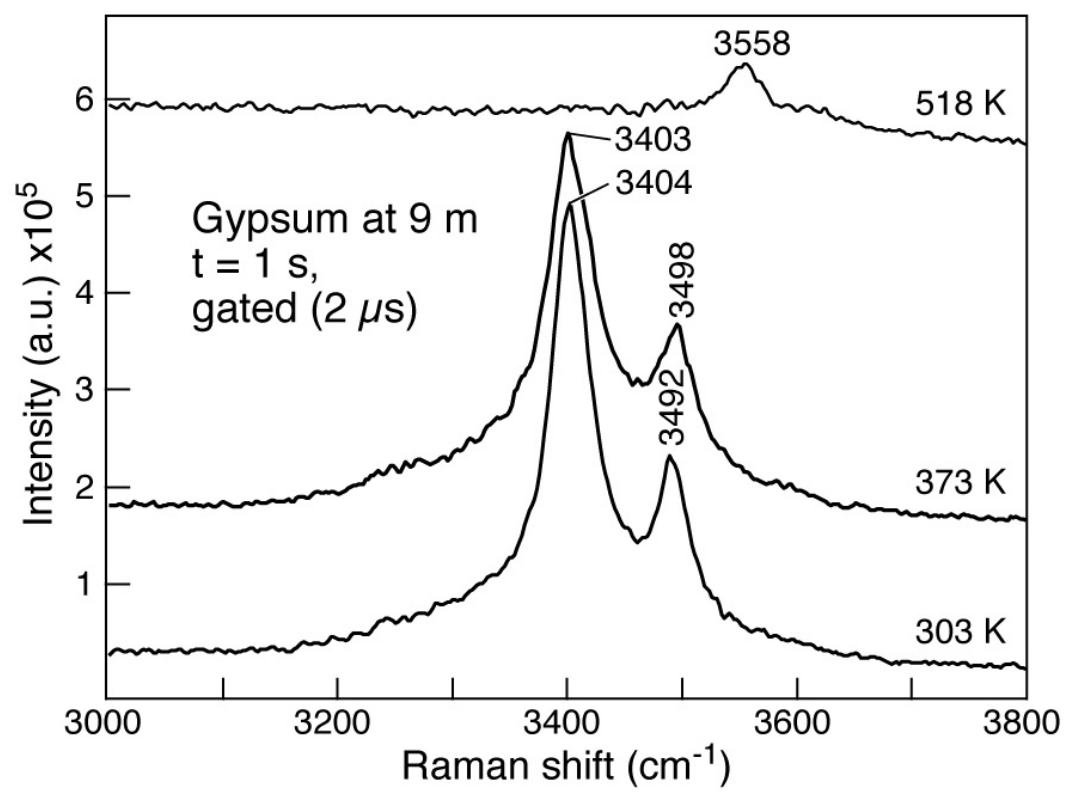

Fig. 5. Time-resolved high-temperature Raman spectra of gypsum at $9 \mathrm{~m}$ in the $3000-3800 \mathrm{~cm}^{-1}$ region. Laser $532 \mathrm{~nm}, 20 \mathrm{~Hz}, 35 \mathrm{~mJ} /$ pulse, averaged over 20 pulses (1 s). 
symmetric stretching mode of sulfate ions in gypsum at various temperatures are listed in Table 1. It is evident from Figs. 4 and 5 that the Raman spectra of gypsum can be measured at high temperatures both in the $100-1300 \mathrm{~cm}^{-1}$ and in the $\mathrm{O}-\mathrm{H}$ stretching region with the time-resolved remote Raman system. On increasing temperature from $303 \mathrm{~K}$ to $373 \mathrm{~K}$, the Raman lines of gypsum in $100-1300 \mathrm{~cm}^{-1}$ region show shift to lower wave number and their line widths increase. The peak position of the $\mathrm{H}_{2} \mathrm{O}$ (I) stretching mode at $3404 \mathrm{~cm}^{-1}$ observed at $303 \mathrm{~K}$ decreases to $3403 \mathrm{~cm}^{-1}$ at 373 $\mathrm{K}$ where as the $\mathrm{H}_{2} \mathrm{O}$ (II) stretching mode of water molecules shows an increase in the peak position to $3498 \mathrm{~cm}^{-1}$ at $373 \mathrm{~K}$ (Table 1). These results are consistent with previous high-temperature micro-Raman laboratory studies of gypsum [1516]. On heating the gypsum sample to $518 \mathrm{~K}$, the $v_{1}\left(\mathrm{SO}_{4}\right)$ peak appears at $1021 \mathrm{~cm}^{-1}$ with line width of $24 \mathrm{~cm}^{-1}$, the $v_{3}\left(\mathrm{SO}_{4}\right)$ anti-symmetric stretching mode of sulfate appears as a doublet (1144 and $\left.1165 \mathrm{~cm}^{-1}\right)$, and in the O-H stretching region a band appears at $3558 \mathrm{~cm}^{-1}$. These changes suggest that there is a phase transition in gypsum. Previous studies have shown that on heating gypsum above $373 \mathrm{~K}$ causes gypsum to lose water molecules during the heating process forming $\gamma-\mathrm{CaSO}_{4}$ (soluble form of anhydrite) and hemihydrate $\left(\mathrm{CaSO}_{4} \cdot 0.5 \mathrm{H}_{2} \mathrm{O}\right.$ also known as bassanite) [15, 17-18]. The Raman $v_{1}\left(\mathrm{SO}_{4}\right)$ lines of hemihydrate and $\gamma$-CaSO4 appear at 1014 and $1026 \mathrm{~cm}^{-1}$, respectively. The large $\left(24 \mathrm{~cm}^{-1}\right)$ line width of the Raman line at $1021 \mathrm{~cm}^{-1}$, the presence of 1014 and $1026 \mathrm{~cm}^{-1}$ doublet and the band at $3558 \mathrm{~cm}^{-1}$ in the $518 \mathrm{~K}$ spectrum indicate that both hemihydrate and $\gamma$-CaSO4 phases are present in the heated sample. Heating of gypsum to $633 \mathrm{~K}$ result in the formation of $\alpha$-CaSO4 (anhydrite) [15].

As the Venus surface temperature is $735 \mathrm{~K}$, hydrous phases of $\mathrm{CaSO}_{4}$ will not be stable and will convert to anhydrite phase. The high-temperature remote Raman measurements on gypsum do exhibit the potential of the technique for searching hydrous phases and their thermal decomposition products on the Venus' surface from a lander. On the basis of high $\mathrm{D} / \mathrm{H}$ ratio (150 times the terrestrial value) in the Venus lower atmosphere, it has been suggested that Venus may have once had a greater abundance of water $[19,20]$. If so, the detection of hydrous minerals on Venus would prove that Venus had more water in the past. Laboratory investigations on hydrous amphibole minerals, such as tremolite, under Venus-like conditions have shown that these minerals if formed on Venus surface during a wetter past could still exist at current conditions on Venus' surface [21].

Table 1. Raman peak positions and line widths (in $\mathrm{cm}^{-1}$ ) of major lines of gypsum, dolomite and olivine at various temperatures

\begin{tabular}{|c|c|c|c|}
\hline Minerals & $T=303 \mathrm{~K}$ & $\mathbf{T}=373 \mathrm{~K}$ & $T=518 K$ \\
\hline \multirow[t]{4}{*}{ Gypsum } & $\begin{array}{c}1008 \\
\left(\omega^{*}=13.3\right)\end{array}$ & $\begin{array}{c}1007 \\
(\omega=13.6)\end{array}$ & $\begin{array}{c}1021 \\
(\omega=25)\end{array}$ \\
\hline & $\begin{array}{c}3401 \\
(\omega=40.5)\end{array}$ & $\begin{array}{c}3400 \\
(\omega=53)\end{array}$ & \\
\hline & $\begin{array}{c}3489 \\
(\omega=41)\end{array}$ & $\begin{array}{c}3496 \\
(\omega=56)\end{array}$ & \\
\hline & & & $\begin{array}{c}3555 \\
(\omega=36)\end{array}$ \\
\hline \multirow[t]{2}{*}{ Dolomite } & $T=303 \mathrm{~K}$ & $\mathrm{~T}=723 \mathrm{~K}$ & $T=973 \mathrm{~K}$ \\
\hline & $\begin{array}{c}1094 \\
(\omega=14.7) \\
\end{array}$ & $\begin{array}{c}1087.5 \\
(\omega=22.2) \\
\end{array}$ & $\begin{array}{c}1081 \\
(\omega=23.8)\end{array}$ \\
\hline \multirow[t]{3}{*}{ Olivine } & $T=303 K$ & $T=718 \mathrm{~K}$ & $\mathrm{~T}=878 \mathrm{~K}$ \\
\hline & $\begin{array}{c}824 \\
(\omega=18.41)\end{array}$ & $\begin{array}{c}816 \\
(\omega=24.5)\end{array}$ & $\begin{array}{c}813 \\
(\omega=29.1)\end{array}$ \\
\hline & $\begin{array}{c}855 \\
(\omega=19.6)\end{array}$ & $\begin{array}{c}850 \\
(\omega=25.4)\end{array}$ & $\begin{array}{c}847 \\
(\omega=26.6)\end{array}$ \\
\hline
\end{tabular}

$\omega=$ Full line width at half-maximum height in $\mathrm{cm}^{-1}$

High-temperature time-resolved Raman spectra of dolomite at $9 \mathrm{~m}$ distance are shown in Fig. 6. The line widths of the $1094 \mathrm{~cm}^{-1}$ Raman line at various temperatures are listed in Table 1. Raman peaks attributed to the lattice and internal modes of dolomite are observed at 174, 297, 723, 1094, 1439, and $1752 \mathrm{~cm}^{-1}[22,23]$. The strongest $1094 \mathrm{~cm}^{-1}$ Raman band is the fingerprint of carbonate ions corresponding to the $v_{1}\left(\mathrm{CO}_{3}\right)$ symmetric stretching mode of carbonate oxygen atoms. The low-frequency Raman bands at 174 and $297 \mathrm{~cm}^{-1}$ are characteristic of dolomite structure. The $723 \mathrm{~cm}^{-1}$ 


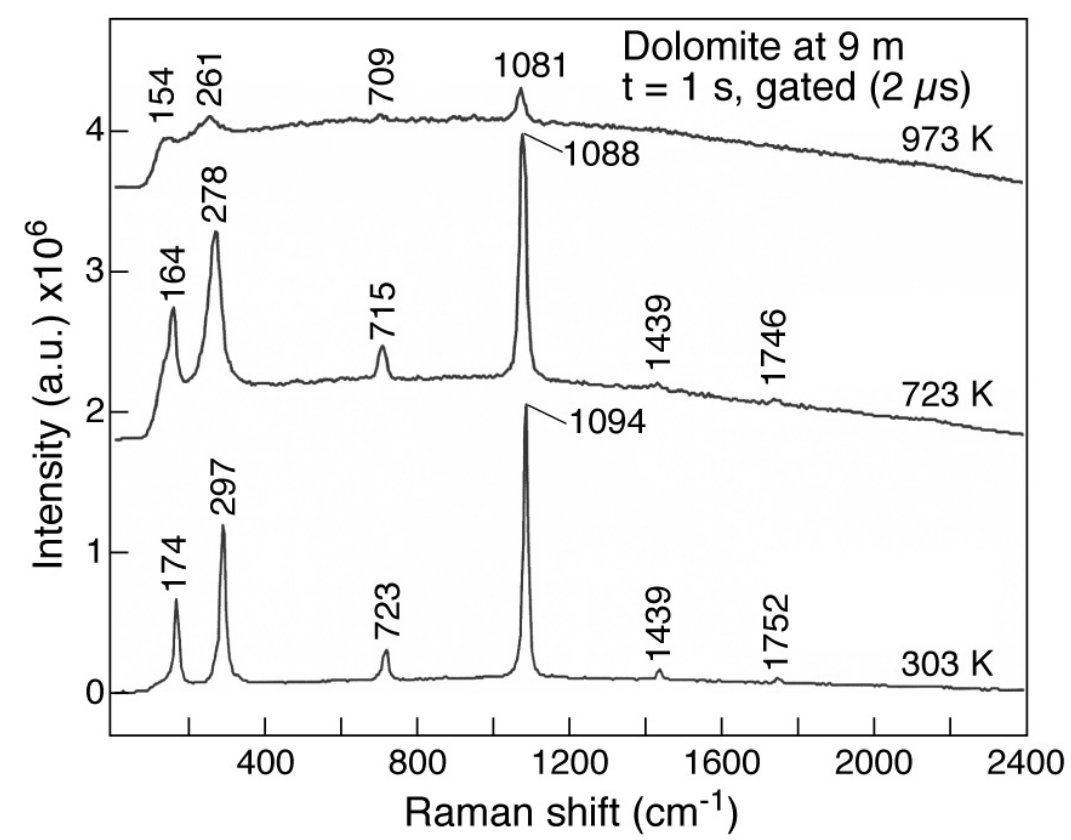

Fig. 6. Time-resolved high-temperature Raman spectra of dolomite at $9 \mathrm{~m}$ in the $100-2400 \mathrm{~cm}^{-1}$ region. Laser $532 \mathrm{~nm} .35 \mathrm{~mJ} /$ pulse. averaged over 20 pulses ( $1 \mathrm{~s}$ ).

band corresponds to the $v_{4}\left(\mathrm{CO}_{3}\right)$ in-plane bending mode, and the very weak band at $1439 \mathrm{~cm}^{-1}$ corresponds to the $v_{3}\left(\mathrm{CO}_{3}\right)$ anti-symmetric stretching mode of carbonate ions. Another weak band at $1752 \mathrm{~cm}^{-1}$ is an overtone mode of the infrared-active $2 v_{2}\left(A_{u}\right)$ mode [22]. In addition, it is possible to distinguish various minerals within the same functional group from each other by the positions of the low-frequency lattice modes and the mid-frequency internal modes [2-3, 22-25]. The lattice modes of dolomite $\left(\mathrm{CaMgCO}_{3}\right)\left(174,297 \mathrm{~cm}^{-1}\right)$, calcite $\left(156\right.$ and $\left.282 \mathrm{~cm}^{-1}\right)$ and magnesite $\left(\mathrm{MgCO}_{3}\right)$ $\left(212\right.$ and $\left.329 \mathrm{~cm}^{-1}\right)$ are widely separated and easily identifiable. Because of their unique Raman patterns and clear, distinguishable peaks, identification of minerals and inorganic compounds by their Raman spectra becomes promising. In fact, Raman spectroscopy can be used as an unambiguous analytical tool for identification of a mineral of interest by comparing its spectra with the library of Raman patterns.

With increasing temperature to $723 \mathrm{~K}$ the Raman lines of dolomite in the time-resolved remote Raman spectrum (Fig. 6) shift to lower frequencies and their widths increase. At $973 \mathrm{~K}$ the Raman spectrum of dolomite shows sudden decrease in the line intensities and there are marked changes in the low-frequency lattice mode region. These changes in the 973 $\mathrm{K}$ Raman spectrum of dolomite indicate phase transition in the material. Differential thermal analysis and high temperature X-ray diffraction studies have shown that on heating dolomite dissociates into $\mathrm{CaCO}_{3}$ and $\mathrm{MgO}$ between 833 and $1038 \mathrm{~K}$ [26]. $\mathrm{MgO}$ is a cubic crystal and therefore in the bulk has no first-order Raman spectrum as it possesses inversion symmetry. It is, therefore, not possible to detect $\mathrm{MgO}$ from the Raman spectrum [27]. The changes in the structure of dolomite on heating to $973 \mathrm{~K}$ are, however, observed in the spectrum of the carbonate phase. The Raman spectrum of dolomite at $973 \mathrm{~K}$ indicates that the sample is an intermediate phase in the thermal decomposition process and partly resembles that of calcite spectrum. These high-temperature Raman measurements suggest that the carbonates could be a stable phase on Venus surface, and could be detected with the time-resolved remote Raman system.

Time-resolved Raman spectra of olivine in a dunite rock, which contains $90 \%$ fine grain olivine crystals, at 303, 718 and $878 \mathrm{~K}$ at $9 \mathrm{~m}$ are shown in Fig. 7. Theses spectra were recorded by integrating the spectra over 200 laser shots. The peak frequency and line widths of the most prominent Raman lines in the $800-850 \mathrm{~cm}^{-1}$ region at various temperatures are listed in Table 1. The intensities of Raman lines of olivine are comparable to those of atmospheric $\mathrm{O}_{2}\left(1556 \mathrm{~cm}^{-1}\right)$ and $\mathrm{N}_{2}\left(2331 \mathrm{~cm}^{-1}\right)$ indicating that olivine is a weaker Raman scatterer than gypsum and dolomite [25]. It was, however, possible to measure Raman spectra of olivine to $878 \mathrm{~K}$ at $9 \mathrm{~m}$ with good signal-to-noise ratio within $10 \mathrm{~s}$. These hightemperature Raman spectra are in agreement with the results of high-temperature laboratory Raman spectroscopic studies of olivine crystals $[27,28]$. 


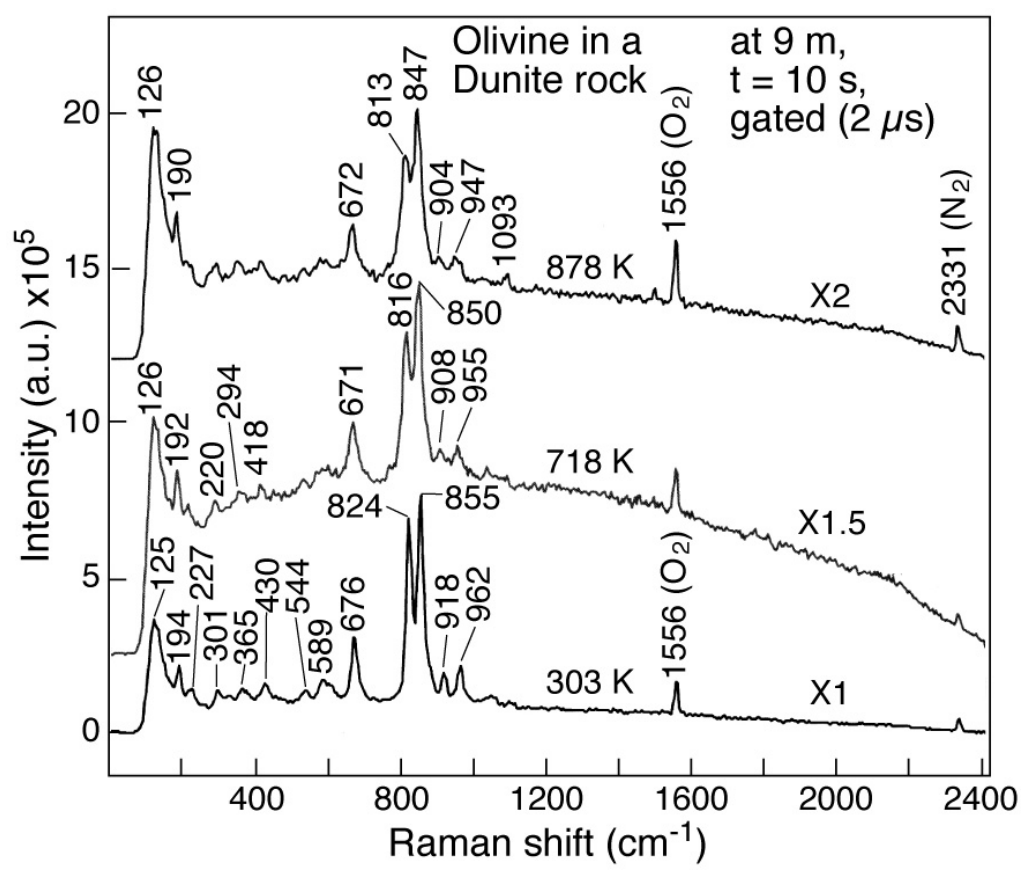

Fig. 7. Time-resolved high-temperature Raman spectra of olivine in a dunite rock at $9 \mathrm{~m}$ in the $100-2400 \mathrm{~cm}^{-1}$ region.

The remote Raman spectrum of olivine at $303 \mathrm{~K}$ shows lines at $125,194,227,365,430,544,589,676,824,855,918$, and 962 $\mathrm{cm}^{-1}$. The 824 and $855 \mathrm{~cm}^{-1}$ doublet in the Raman spectrum of olivine at $303 \mathrm{~K}$ is the Raman fingerprint of olivine.

Forsterite $\left(\mathrm{Fo}, \mathrm{Mg}_{2} \mathrm{SiO}_{4}\right)$ and fayalite $\left(\mathrm{Fay}, \mathrm{Fe}_{2} \mathrm{SiO}_{4}\right)$ are the end member minerals of olivine group. In forsterite at room temperature the signature double peaks are observed at 825 and $857 \mathrm{~cm}^{-1}$. The corresponding Raman lines of fayalite at room temperature appear at 812 and $835 \mathrm{~cm}^{-1}$. These Raman lines are due to the $v_{1}$ - and $v_{3}$-derived vibrational modes of orthosilicate $\left(\mathrm{SiO}_{4}\right)$ units. The $v_{1}$ and $v_{3}$, respectively, correspond to $\mathrm{Si}-\mathrm{O}_{\mathrm{nb}}$ symmetric and anti symmetric stretching modes of the $\mathrm{SiO}_{4}{ }^{4-}$ tetrahedra, where $\mathrm{O}_{\mathrm{nb}}$ refers to non-bridging oxygen. The frequencies of these $v_{1}$ and $v_{3}$-derived modes show small variation with substitution of $\mathrm{Fe}$ or $\mathrm{Ca}$ for $\mathrm{Mg}$ [28-33]. Presence of Raman lines at 824 and $855 \mathrm{~cm}^{-1}$ indicate that the dunite rock contains Fo-rich olivine crystals.

On increasing the temperature of olivine crystals in dunite rock to $718 \mathrm{~K}$ the Raman lines shift to lower frequency and their band widths increase (Table 1). This trend continues to $878 \mathrm{~K}$, a temperature that is higher than the Venus surface temperature of $\sim 735 \mathrm{~K}$. In the olivine spectrum at $878 \mathrm{~K}$, the line widths of 813 and $847 \mathrm{~cm}^{-1}$ Raman line are, respectively, 29.1 and 26.6 $\mathrm{cm}^{-1}$. Evidently time-resolved remote Raman system could easily detect olivine on the Venus surface.

Figure 8 depicts time-resolved Raman spectra of low clinoentatite measured at a distance of $75 \mathrm{~mm}$ from the collecting lens inside the furnace at $293,373,473,673$ and $873 \mathrm{~K}$ [11]. In the spectrum at $293 \mathrm{~K}$, the $v_{\mathrm{s}}(\mathrm{Si}-\mathrm{O}-\mathrm{Si})$ modes of silicate chains appear at 668.6 and $691.5 \mathrm{~cm}^{-1}$, and the $v_{\mathrm{s}}\left(\mathrm{Si}-\mathrm{O}_{\mathrm{nbr}}\right)$ modes of silicon-non-briding oxygen stretch of the pyroxene chain appear at 1007.3 and $1027.3 \mathrm{~cm}^{-1}$.

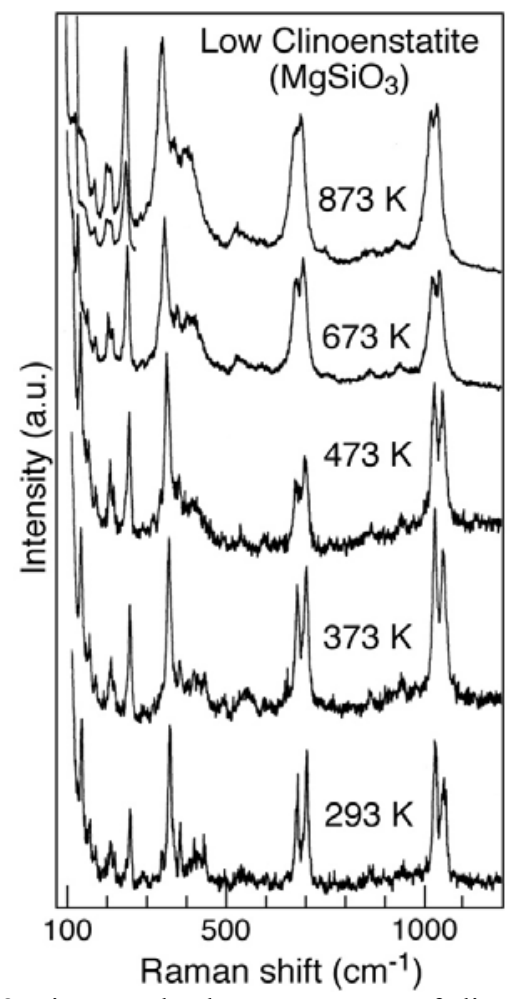

Fig. 8. Time-resolved Raman spectra of clinoenstatite at high-temperatures. (Sample at $75 \mathrm{~mm}$ from collection optics in side the furnace) 
Table 2. Peak positions and line width $\left(\right.$ in $\left.\mathrm{cm}^{-1}\right)$ of strong Raman lines of low clinoenstatite at selected temperatures

\begin{tabular}{|c|c|c|c|}
\hline $\mathbf{2 9 3} \mathbf{~ K}$ & $\mathbf{4 7 3 ~ K}$ & $\mathbf{8 7 3 ~ K}$ & Assignments \\
\hline $\begin{array}{c}668.6 \\
\left(\omega^{*}=10.7\right)\end{array}$ & $\begin{array}{c}665.7 \\
(\omega=17.9)\end{array}$ & $\begin{array}{c}663 \\
(\omega=20.7)\end{array}$ & $v_{\mathrm{s}}(\mathrm{Si}-\mathrm{O}-\mathrm{Si})$ \\
\hline $\begin{array}{c}691.6 \\
(\omega=10.7)\end{array}$ & $\begin{array}{c}688.2 \\
(\omega=17.9)\end{array}$ & $\begin{array}{c}683.6 \\
(\omega=17.8)\end{array}$ & $v_{\mathrm{s}}(\mathrm{Si}-\mathrm{O}-\mathrm{Si})$ \\
\hline 1015.2 & 1012.0 & 1007.3 & $v_{\mathrm{s}}\left(\mathrm{Si}-\mathrm{O}_{\mathrm{nbr}}\right)$ \\
$(\omega=12)$ & $(\omega=16)$ & $(\omega=20.6)$ & \\
\hline 1037.4 & 1034.6 & 1027.3 & $v_{\mathrm{s}}\left(\mathrm{Si}_{-} \mathrm{O}_{\mathrm{nbr}}\right)$ \\
$(\omega=15)$ & $(\omega=15.6)$ & $(\omega=18.3)$ & \\
\hline
\end{tabular}

$*_{\omega}=$ Full line width at half maximum height $\left(\right.$ in $\left.\mathrm{cm}^{-1}\right)$

With increasing temperature all the Raman lines of clinoenstatite shift toward lower wave number and their line widths increase. The frequencies and the line width of the $v_{\mathrm{s}}(\mathrm{Si}-\mathrm{O}-\mathrm{Si})$ and $v_{\mathrm{s}}\left(\mathrm{Si}-\mathrm{O}_{\mathrm{nbr}}\right)$ modes at selected temperatures are listed in Table 2. It is clear from Fig. 8 that even at $873 \mathrm{~K}$ the Raman spectrum of clinoenstatite has good signal to noise ratio, and the fingerprint lines of pyroxene corresponding to $v_{\mathrm{s}}(\mathrm{Si}-\mathrm{O}-\mathrm{Si})$ and $v_{\mathrm{s}}\left(\mathrm{Si}-\mathrm{O}_{\mathrm{nbr}}\right)$ modes are clearly visible. Evidently, time-resolved Raman spectroscopic technique can be used on Venus surface for investigating mineralogy of silicate minerals both at short $(75 \mathrm{~mm})$ and at relatively long distance of $9 \mathrm{~m}$. We have demonstrated that the time-resolved Raman spectroscopy can be used for investigating Venus surface mineralogy including silicates, carbonates, sulfates and hydrous and anhydrous minerals.

Figure 9 shows a time-resolved remote Raman spectrum of carbon dioxide $\left(\mathrm{CO}_{2}\right)$ at 1 atm in fish tank of $120 \mathrm{~cm}$ length at $9 \mathrm{~m}$ distance. In Raman spectroscopy, the $v_{1}$ totally symmetric stretching vibration of $\mathrm{CO}_{2}\left(1305.4 \mathrm{~cm}^{-1}\right)$ is active for the isolated molecule (e.g., the monomer) and is in Fermi resonance with the $2 v_{2}$ overtone of the bending mode of the molecule $\left(v_{2} \sim 667 \mathrm{~cm}^{-1}\right)$. As a consequence, two intense peaks are observed giving rise to the so-called Fermi doublet, situated at 1285 and $1388 \mathrm{~cm}^{-1}$. The spectrum in Fig. 9 clearly shows a Fermi resonance doublet of $\mathrm{CO}_{2}$ molecules at $1285\left(2 v_{2}\right)$ and $1388\left(v_{1}\right) \mathrm{cm}^{-1}$. Additional Raman lines (Fig. 9) at 575 and $1091 \mathrm{~cm}^{-1}$ are, respectively, $v_{\mathrm{s}}(\mathrm{Si}-\mathrm{O}-\mathrm{Si})$ symmetric stretching of bridging oxygen, and $v_{\mathrm{s}}\left(\mathrm{Si}_{-} \mathrm{O}_{\mathrm{nbr}}\right)$ stretching modes of non-bridging oxygen of the glass wall.

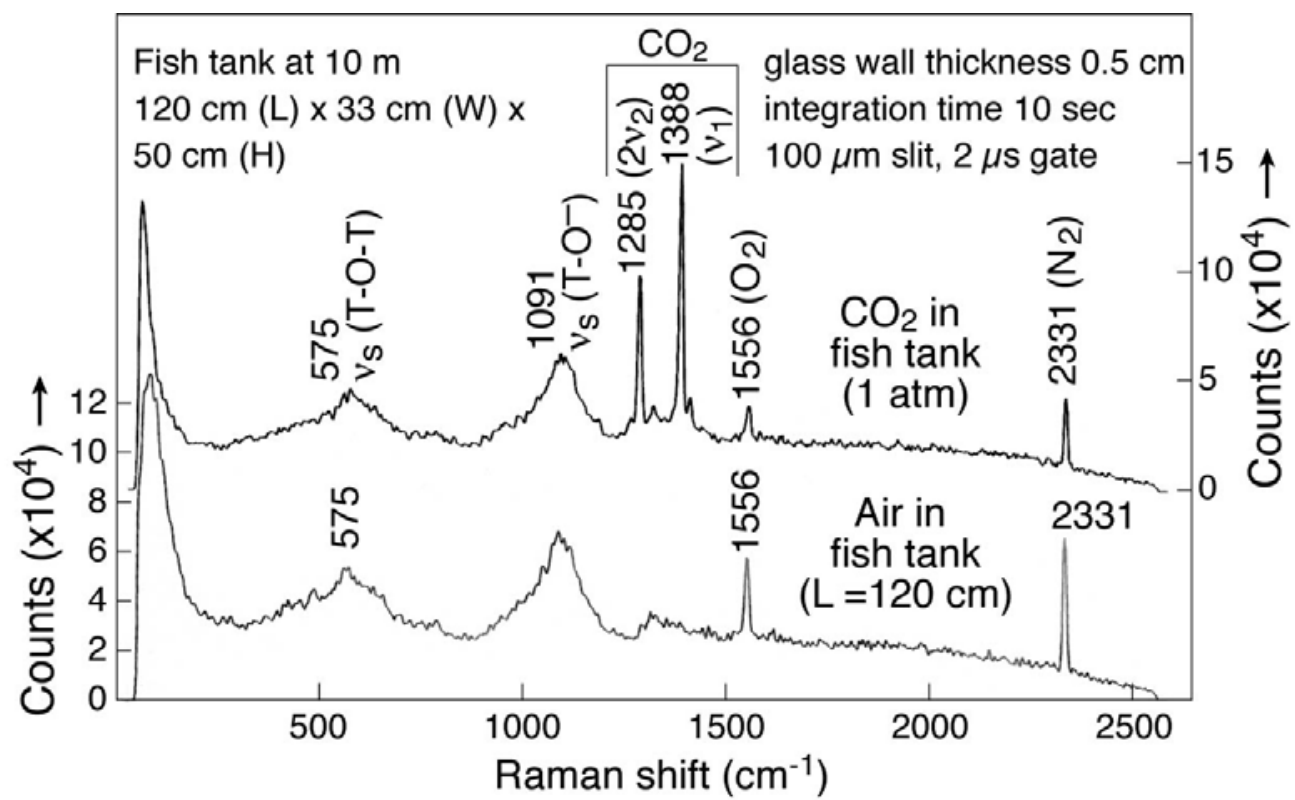

Fig. 9 Raman spectra of air and $\mathrm{CO}_{2}$ in a fish tank at $9 \mathrm{~m}$ within a well illuminated laboratory. Laser $532 \mathrm{~nm}, 35 \mathrm{~mJ} /$ pulse, $20 \mathrm{~Hz}$, spectra averaged over 200 laser shots.

The sharp lines at 1556 and $2331 \mathrm{~cm}^{-1}$ are, respectively, the symmetric stretching modes of atmospheric oxygen and nitrogen molecules. On the Venus surface, $\mathrm{CO}_{2}$ pressure will be $\sim 90 \mathrm{~atm}$. The Raman spectrum will be dominated by 
the 1285 and $1388 \mathrm{~cm}^{-1}$ lines. Laboratory Raman spectroscopic investigation of supercritical $\mathrm{CO}_{2}$ in the pressure range of 0.1 to $35 \mathrm{MPa}$ and at temperatures of $307,309,313$, and $323 \mathrm{~K}$ have shown formation of transient $\mathrm{CO}_{2}$ dimers as indicated by the presence of the $v_{2}$ bending mode (forbidden transition at about $668 \mathrm{~cm}^{-1}$ ) in the spectrum [34]. Figure 10 shows the positions of the strong Raman lines of various molecular species in the gas phase at 1 atm pressure and room temperature [35]. As the Raman lines of molecular gases are relatively sharp and will remain well defined at Venus atmospheric pressure and temperature, and will increase in intensity with increasing pressure, these lines can be used for profiling molecular species in Venus atmosphere. The elastic scattered light could provide profiles of particulates in Venus atmosphere by operating the Raman system in Mie-Rayleigh lidar mode [e.g., 24, 36].

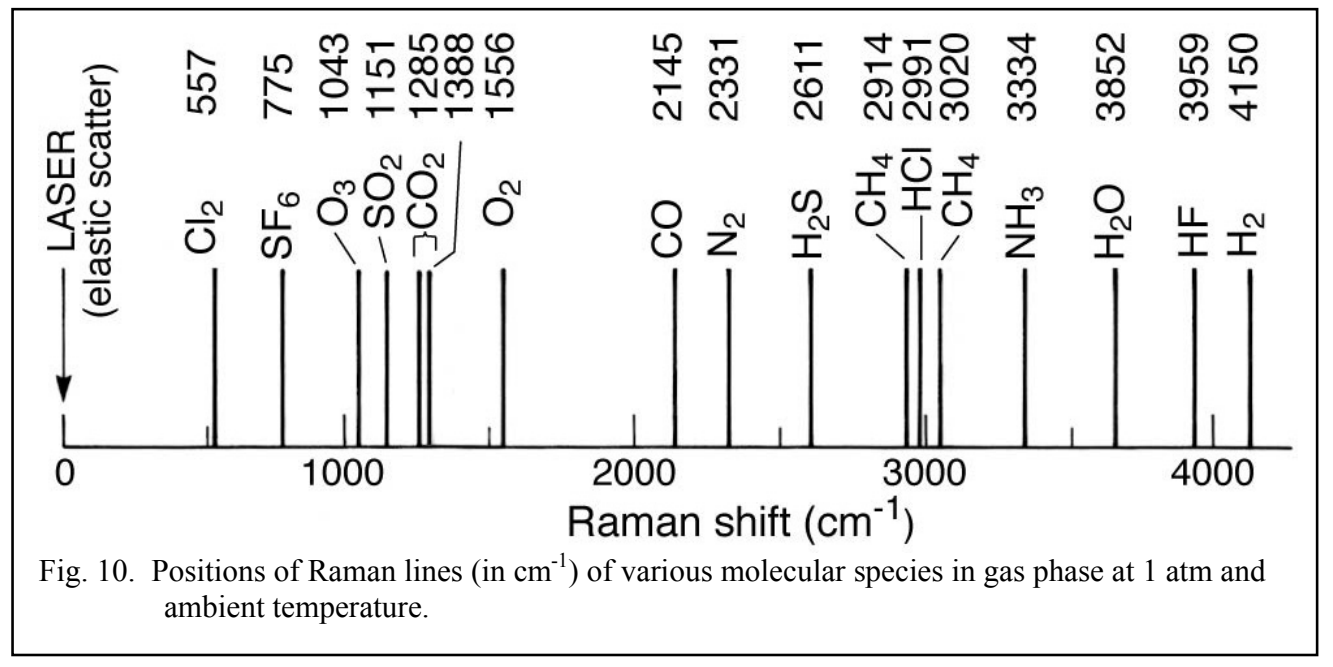

\section{CONCLUSIONS}

We have demonstrated that it is feasible to measure good quality Raman spectra of minerals at high-temperature with a time-resolved remote Raman system during daytime and nighttimes. The results of the present investigation have also shown that Raman spectroscopy could provide information about the hydrous and anhydrous sulfate, carbonate and silicate minerals at high temperatures. The dehydration and decarbonation of minerals at high temperatures can be monitored from the reaction products of these minerals. In the case of dolomite it is found that mineral partially dissociate in to calcite and $\mathrm{MgO}$. It seems that some of the carbonate minerals could survive on Venus surface under current conditions. The time-resolved Raman system is also capable of measuring molecular species in the atmosphere. The time-resolved Raman system could be very useful in future lander and rover missions to Venus for investigating surface mineralogy and profiling molecular species in Venus atmosphere during descending of the space crafts as well as on the surface.

\section{ACKNOWLEDGEMENTS}

This work has been supported in part by NASA under the MIDP grant \#NNX08AR10G. The authors would like to thank Nancy Hulbirt and Diane Henderson for their valuable help with figures and editing, respectively. This is School of Ocean and Earth Science and Technology contribution no. \#7575, and HIGP contribution no. \#1698.

\section{REFERENCES}

1. Wang, A., B. L. Jolliff, and L. A. Haskin, Raman spectroscopy as a method for mineral identification on lunar robotic exploration missions, J. Geophys. Res. 100, 21,189- 21,199 (1995).

2. Sharma, S. K., S. M. Angel, M. Ghosh, H. W. Hubble, and P. G. Lucey, A remote pulsed-laser Raman spectroscopy system for mineral analysis on planetary surfaces to 66 meters, Appl. Spectrosc. 56, 699-705 (2002).

3. Sharma, S. K., P. G. Lucey, M. Ghosh, H. W. Hubble, and K. A. Horton, Stand-off Raman Spectroscopic Detection of Minerals on Planetary Surfaces, Spectrochim. Acta, A 59, 2391-2407 (2003). 
4. Misra, A. K., S. K. Sharma, C. H. Chio, P. G. Lucey, and B. Lienert, Raman system for daytime measurements of mineral spectra, Spectrochim Acta, A 61, 2281-2287(2005).

5. Sharma, S. K., A. K. Misra, P. G. Lucey, S. M. Angel, C. P. McKay, Remote pulsed Raman spectroscopy of inorganic and organic materials to a radial distance of 100 meters, Appl. Spectrosc. 60, 871-876 (2006).

6. Misra, A. K., S.K. Sharma and P.G. Lucey, Remote Raman spectroscopic detection of minerals and organics under illuminated condition from $10 \mathrm{~m}$ distance using a single $532 \mathrm{~nm}$ laser pulse, Appl. Spectrosc. 60, 223-228 (2006)

7. Sharma, S. K. (2007) New trends in telescopic remote Raman spectroscopic instrumentation, Spectrochim. Acta, A 68, 1008-1022 (2007).

8. Moroz, V. I., Studies of the atmosphere of Venus by means of spacecraft: solved and unsolved problems. Adv. Space Res. 29, 215-225 (2002).

9. NRC, "New Frontiers in the Solar System, an integrated exploration strategy," Technical report, Space Studies Board, National Research Council, Washington, D.C., (2003).

10. SSE Roadmap Team, "Solar System Exploration - This is the Solar System Exploration Roadmap for NASA's Science Mission Directorate," Technical Report JPL D-35618, National Aeronautics and Space Administration,

11. VEXAG, Venus Exploration Goals, Objectives, Investigations, and Priorities: 2007, A report by Venus Exploration Analysis Group, pp.55 October (2007) http://www.lpi.usra.edu/vexag/vexag_goals 2007.pdf

12. Sharma, S. K., Applications of advanced Raman techniques in earth sciences, Vib. Spectra Struc..2 17B, . 513-568 (1989).

13. Gillet, P., Raman spectroscopy at high pressure and high temperature - Phase transitions and thermodynamic properties of minerals, Phys. Chem. Minerals, 23, 263-275 (1996).

14. NIST Standard Reference Database Website: http://webbook.nist.gov/chemistry/

15. Prasad, P. S. R., A. Pradhan and T. N. Gowd, In situ micro-Raman investigation of dehydration mechanism in natural, Gypsum, Current Sci., 80, 1203-1207 (2001).

16. Chio, C. H., S. K. Sharma, and D. W. Muenow, Micro-Raman study of gypsum in the temperature range between 9 K and 373 K, Amer. Mineral. 89, 390-395 (2004)

17. Abrie, W., K. Reisdorf and J. Pametier, Dehydration reaction of gypsum: a neutron and x-ray diffraction study. J. Solid State Chem., 29, 23-30 (1990)

18. Chang, H., P. J. Huang and S. C. Hou Application of thermal Raman spectroscopy to study of CaSO4-2H2O and $\mathrm{CaSO}_{4} \cdot 0.5 \mathrm{H}_{2} \mathrm{O}$, Mat. Chem. Phys. 58, $12-19$ (1999).

19. Donahue, T. M., D. H. Grinspoon, R. E. Hartle and R. R. Hodges, Ion/neutral escape of hydrogen and deuterium: evolution of water, in: Bougher, S.W., Hunten, D.M., Phillips, R.J. (Eds.), Venus II. Univ. of Arizona Press, Tucson, pp. 385-414 (1997).

20. Svedhem, H., D. V. Titov, F. W. Taylor and O. Witasse, Venus as a more Earth-like planet, Nature, 450, 629632 (2007).

21. Johnson, N. M., and B. Fegley, Jr., Tremolite decomposition on Venus II. Products, kinetics, and mechanism, Icarus 164, 317-333 (2003).

22. Bischoff, W. D., S. K. Sharma, and F. T. Mackenzie, Carbonate ion disorder in synthetic and biogenic magnesian calcites: A Raman spectral study, Amer. Mineral. 70, 581-589 (1985)

23. McMillan, P. F., and A. M. Hofmeister, Infrared and Raman spectroscopy in F.C. Hawthorne (Ed.), Spectroscopic Methods in Mineralogy and Geology, Review in Mineralogy, 18, p. 99. Mineralogical Society of America, Washington, D. C., 1988. 
24. Sharma, S. K., J. N. Porter, A. K. Misra, H. W. Hubble, and P. Menon, Portable standoff Raman and MieRayleigh lidar for cloud, aerosol, and chemical monitoring, Proc. SPIE, 5154, 1-14 (2003).

25. Stopar, J. D., P. G. Lucey, S. K. Sharma, A. K. Misra, G. J. Taylor, H. W. Hubble, Raman efficiencies of natural rocks and minerals: Performance of a remote Raman system for planetary exploration at a distance of 10 meters., Spectrochim Acta, A 61, 2315-2323 (2005).

26. Engler, P., M. Santana, W. Mark, M. L. Mittleman and D. Balazs, Nonisothermal, in situ XRD analysis of dolomite decomposition, Thermochim. Acta, 140, 67-76 (1989).

27. Schlecht, R. G., and H. K. Böckelmann, Raman Scattering from Microcrystals of MgO, Phys. Rev. Lett. 31, 930 - 932 (1973).

28. Gillet, P., P. Richet, F. Guyot, G. Fiquet, High-temperature thermodynamic properties of forsterite, J. Geophys. Res. 96 (B7) 11,805-11816 (1991)

29. Sharma, S. K., T. F. Cooney and S.-Y. Wang, Effect of high temperature on olivines - A Raman spectral study, Proc. XIII AIRAPT - International Conf. on High Pressure Sci. and Tech, Oxford \& IBH Publ. Co., New Delhi, India, pp. 614-619 (1991).

30. Piriou, B., and P. McMillan, The high frequency vibrational spectra of vitreous and crystalline orthosilicates, Amer. Mineral. 68, 426-443 (1983).

31. Lam, P. K., R. Yu, M. W. Lee and S. K. Sharma, Relationship between crystal structure and vibrational modes in $\mathrm{Mg}_{2} \mathrm{SiO}_{4}$. Am. Mineral., 75, 109-119 (1990).

32. Chopelas, A., Single crystal Raman spectra of forsterite, fayalite, and monticellite, Amer. Mineral. 76, 11011109 (1991).

33. Mohanan, K., S. K. Sharma and F. C. Bishop, Raman spectral study of forsterite-monticellite solid solutions. Amer. Mineral., 78, 42-48, 1993.

34. Cabaço, M. I., S. Longelin,Y. Danten and M. Besnard, Transient dimer formation in supercritical carbon dioxide as seen from Raman scattering, J. Chem. Phys. 128, 074507/1- 074507/10 (2008).

35. Measures, R. M., Laser Remote Sensing - Fundamental and Applications, Krieger Publishing Co., Malabar, Florida, USA, Reprint Edition (1992).

36. Sharma, S. K., B. R. Lienert, J. N. Porter and A. D. Clarke, Scanning lidar imaging of marine aerosol fields generated by breaking waves, in U. N. Singh, S. Ismail, and G. K. Schwemmer (eds.) Proc. $19^{\text {th }}$ Intern. Laser Radar Conf., July 6-10, 1998, Annapolis, Maryland, Part 2, pp. 673-676, NASA Langley Research Center, Hampton, Virginia, USA (1998). 